\title{
Risk-of-bias Assessment
}

Supplement to: Makam RCP, Hoaglin DC, McManus DD, Wang V, Gore JM, Spencer FA, Pradhan R, Tran H, Yu H, Goldberg RJ. Efficacy and safety of direct oral anticoagulants approved for cardiovascular indications: systematic review and meta-analysis. 


\begin{tabular}{|c|c|c|c|c|c|c|c|c|c|}
\hline & \multicolumn{4}{|c|}{ NVAF Studies } & \multicolumn{5}{|c|}{ VTE Studies } \\
\hline & ARISTOTLE & $\begin{array}{l}\text { RE-LY } \\
150\end{array}$ & $\begin{array}{l}\text { ROCKET } \\
\text { AF }\end{array}$ & $\begin{array}{l}\text { ENGAGE } \\
\text { AF }\end{array}$ & AMPLIFY & $\begin{array}{l}\text { EINSTEIN- } \\
\text { DVT }\end{array}$ & $\begin{array}{l}\text { Hokusai- } \\
\text { VTE }\end{array}$ & $\begin{array}{l}\text { RE- } \\
\text { COVER }\end{array}$ & $\begin{array}{l}\text { RECOVER- } \\
2\end{array}$ \\
\hline $\begin{array}{l}\text { Random sequence } \\
\text { generation } \\
\text { (selection bias) }\end{array}$ & Low risk & Low risk & Low risk & Low risk & Low risk & Low risk & Low risk & $\begin{array}{l}\text { Low } \\
\text { risk }\end{array}$ & Low risk \\
\hline $\begin{array}{l}\text { Allocation } \\
\text { concealment } \\
\text { (selection bias) }\end{array}$ & Low risk & Low risk & Low risk & Low risk & Low risk & Low risk & Low risk & $\begin{array}{l}\text { Low } \\
\text { risk }\end{array}$ & Low risk \\
\hline $\begin{array}{l}\text { Blinding of } \\
\text { participants and } \\
\text { personnel } \\
\text { (performance bias) }\end{array}$ & Low risk & $\begin{array}{l}\text { Unclear } \\
\text { risk }\end{array}$ & Low risk & Low risk & Low risk & $\begin{array}{l}\text { Unclear } \\
\text { risk }\end{array}$ & Low risk & $\begin{array}{l}\text { Low } \\
\text { risk }\end{array}$ & Low risk \\
\hline $\begin{array}{l}\text { Blinding of outcome } \\
\text { assessment } \\
\text { (detection bias) } \\
\text { (patient-reported } \\
\text { outcomes) }\end{array}$ & Low risk & $\begin{array}{l}\text { Unclear } \\
\text { risk }\end{array}$ & Low risk & Low risk & Low risk & $\begin{array}{l}\text { Unclear } \\
\text { risk }\end{array}$ & Low risk & $\begin{array}{l}\text { Low } \\
\text { risk }\end{array}$ & Low risk \\
\hline $\begin{array}{l}\text { Blinding of outcome } \\
\text { assessment } \\
\text { (detection bias) } \\
\text { (Mortality) }\end{array}$ & Low risk & $\begin{array}{l}\text { Unclear } \\
\text { risk }\end{array}$ & Low risk & Low risk & Low risk & $\begin{array}{l}\text { Unclear } \\
\text { risk }\end{array}$ & Low risk & $\begin{array}{l}\text { Low } \\
\text { risk }\end{array}$ & Low risk \\
\hline $\begin{array}{l}\text { Incomplete outcome } \\
\text { data addressed } \\
\text { (attrition bias) }\end{array}$ & Low risk & $\begin{array}{l}\text { Unclear } \\
\text { risk }\end{array}$ & Low risk & Low risk & Low risk & Low risk & $\begin{array}{l}\text { Unclear } \\
\text { risk }\end{array}$ & $\begin{array}{l}\text { Unclear } \\
\text { risk }\end{array}$ & Low risk \\
\hline $\begin{array}{l}\text { Selective reporting } \\
\text { (reporting bias) }\end{array}$ & Low risk & $\begin{array}{l}\text { Unclear } \\
\text { risk }\end{array}$ & Low risk & Low risk & Low risk & Low risk & Low risk & $\begin{array}{l}\text { Low } \\
\text { risk }\end{array}$ & Low risk \\
\hline $\begin{array}{l}\text { Summary } \\
\text { Judgment }\end{array}$ & Low risk & $\begin{array}{l}\text { Unclear } \\
\text { risk }\end{array}$ & $\begin{array}{l}\text { Low } \\
\text { risk }\end{array}$ & $\begin{array}{l}\text { Low } \\
\text { risk }\end{array}$ & Low risk & $\begin{array}{l}\text { Unclear } \\
\text { risk }\end{array}$ & Low risk & $\begin{array}{l}\text { Low } \\
\text { risk }\end{array}$ & Low risk \\
\hline
\end{tabular}

